\title{
Efecto del resveratrol en el porcentaje y calidad de embriones in vitro generados por separación de blastómeras en bovinos
}

\author{
Portocarrero, G.T.'; Cortez, J.V.'; Murga, N.L.'; Beloti, K.³; Encina, R. ${ }^{1}$ \\ ${ }^{1}$ Lab. Biotecnol. Anim. Reprod. \& Mej. Genét., Univ. Nac. T. R. Mendoza, Chachapoyas, Amazonas, Perú. \\ ${ }^{2}$ Lab. Catalina Genetics, Sydney, Australia. ${ }^{3}$ Lab. Embryo Rio Preto, São Paulo, Brasil. \\ E-mail: glenytatty@gmail.com
}

\begin{abstract}
Resumen
Portocarrero, G.T.; Cortez, J.V.; Valderrama, N.L.; Beloti, K.; Encina, R.: Efecto del resveratrol en el porcentaje y calidad de embriones in vitro generados por separación de blastómeras en bovinos. Rev. Vet. 32: 1, 101-105, 2021. El estado oxidativo es un factor importante que determina el desarrollo de embriones bovinos. El objetivo de este estudio fue evaluar el efecto del resveratrol en el porcentaje y calidad de embriones in vitro generados por separación de blastómeras en ganado bovino. Ovocitos provenientes de matadero fueron madurados y fecundados in vitro por el método convencional. Terminada las 18 horas de fecundación, los cigotos se cultivaron por 3 días en medio fluido oviductual sintético (SOF) para el control y suplementado con $2 \mu \mathrm{M}$ y $0,5 \mu \mathrm{M}$ para los tratamientos. Al día 3 se despojaron de su zona pelúcida (ZP) para ser cultivados a razón de cuatro blastómeras en well of thewell (WOW) por 6 días en medio SOF suplementado con resveratrol. Se evaluaron datos porcentuales de clivaje y división embrionaria ( 8 a 10 blastómeros) a los 3 días de cultivo superando la suplementación con $0.5 \mu \mathrm{M}$ de resveratrol $(\mathrm{p}<0,05)$. A los 6 días post separación de blastómeras se evaluó porcentaje de embriones, cantidad de células totales, células vivas y células muertas, utilizando la tinción Hoechst, FDA y PI respectivamente. No hubo diferencias en el porcentaje de blastocistos entre tratamientos; sin embargo, la suplementación con $0,5 \mu \mathrm{M}$ de resveratrol al medio SOF tuvo mayor cantidad de células totales y células vivas $(\mathrm{p}<0,05)$. Finalmente la suplementación con resveratrol al medio SOF no aumenta el porcentaje de blastocistos pero sí mejora su calidad usando una concentración de $0,5 \mu \mathrm{M}$.
\end{abstract}

Palabras clave: clivaje, desarrollo embrionario, células totales, células vivas.

\begin{abstract}
Portocarrero, G.T.; Cortez, J.V.; Valderrama, N.L.; Beloti, K.; Encina, R.: Effect of resveratrol on the percentage and quality of in vitro embryos generated by separation of blastomeres in cattle. Rev. Vet. 32: 1, 101-105, 2021. The oxidative state is an important factor that determines the development of bovine embryos. The objective in this study was to evaluate the effect of resveratrol on the quality of in vitro embryos generated by separation of blastomeres in cattle. Oocy tes from the slaughterhouse were matured and fertilized in vitro by the conventional method. After 18 hours of fertilization, the zygotes were cultured for 3 days in synthetic oviductual fluid medium (SOF) for control and supplemented with $2 \mu \mathrm{M}$ and $0.5 \mu \mathrm{M}$ for the treatments. On day 3 they were stripped of their zona pellucida (ZP) to be cultivated at a rate of four blastomeres in well of the well (WOW) for 6 days in medium SOF supplemented with resveratrol. We evaluated percentage data of cleavage and embryonic division ( 8 to 10 blastomeres) after 3 days of culture, finding a significant difference $p<0.05$ with supplementation with $0.5 \mu \mathrm{M}$ of resveratrol. At 6 days after blastomeres separation, percentage of embryos, number of total cells, live cells and dead cells were evaluated using Hoechst, FDA and PI staining respectively. There were no differences in the percentage of blastocysts between treatments; however, supplementation with $0.5 \mu \mathrm{M}$ of resveratrol to the SOF medium had a greater amount of total cells and living cells $(\mathbf{p}<0.05)$. In conclusion, supplementation with resveratrol in the SOF medium does not increase the percentage of blastocysts but improves its quality using a concentration of $0.5 \mu \mathrm{M}$.
\end{abstract}

Key words: clivage, embryonic development, total cells, living cells. 


\section{INTRODUCCIÓN}

En la actualidad existe una gran competitividad en el sector ganadero. En todo momento se busca producir cantidad y calidad, siendo ello un motivo importante para el uso de biotecnologías reproductivas. La producción de embriones in vitro es una biotecnología reproductiva empleada a nivel mundial, por sus diversas aplicaciones en la mejora genética animal.

Sin embargo la baja tasa de desarrollo embrionario in vitro causada por diversos factores como la mala calidad de los gametos, anomalías cromosómicas, desacoplamiento de telómeros y condiciones de cultivo que no son óptimas, inducen el estrés oxidativo resultando una gran limitante en la producción de embriones in vitro como herramienta reproductiva y posterior aplicación en la mejora genética.

Los embriones producidos in vitro son muy susceptibles al estrés oxidativo y consecuentemente tienen problemas en su desarrollo. El estrés oxidativo ha sido relacionado con diferentes tipos de lesiones celulares, peroxidación de lípidos de membrana, oxidación de aminoácidos y ácidos nucleicos, apoptosis y necrosis, que posteriormente disminuyen la viabilidad de los embriones producidos in vitro 7,8

El resveratrol es un polifenol natural presente en numerosas plantas y frutos como cacahuetes, moras, arándanos $\mathrm{y}$, sobre todo, en la uva y el vino tinto ${ }^{3}$. Recientemente se ha observado un aumento en el interés por el resveratrol tras los hallazgos beneficiosos sobre la quimioprevención, la cardioprotección, los procesos inflamatorios y varios aspectos del metabolismo, aumentando la vida útil de varios organismos, desde levaduras hasta vertebrados ${ }^{15}$.

Mediante este descubrimiento se han realizado varios estudios con el objetivo de identificar funciones biológicas del resveratrol en la reproducción de mamíferos ${ }^{5,9}$. La adición de resveratrol como suplemento a los medios de cultivo en la producción de embriones in vitro es utilizado en diversas especies.

En una investigación se adicionaron $2 \mu \mathrm{M}$ de resveratrol en soluciones de MIV mejorando y optimizando la calidad y resistencia de los ovocitos porcinos a la crioconservación ${ }^{4}$. Otros utilizaron el resveratrol a una concentración de $0.5 \mu \mathrm{M}$ obteniendo un efecto beneficioso sobre el desarrollo de pre-implantación que conduce a la formación de blastocistos y una mejor calidad del embrión ${ }^{10}$

En bovinos la adición de resveratrol al medio CIV o medio de vitrificación, ayudó a los embriones a recuperar parcialmente su estado inicial en el proceso de vitrificación y calentamiento ${ }^{2} \mathrm{y}$ en ratones promovieron la calidad de los ovocitos al prevenir el daño al $\mathrm{ADN}^{12}$.

La técnica de separación de blastómeras es utilizada como una herramienta para aumentar la producción de células embrionarias (embriones) ${ }^{6}$. Sin embargo, no se han probado los beneficios que el resveratrol puede tener en el proceso de producción de embriones in vitro por la técnica de separación de blastómeras, con la fi- nalidad de aumentar los porcentajes y la calidad de los embriones producidos in vitro y de esta manera brindar un beneficio social entregando a menor costo los embriones y mejorando la genética a nivel de la región y del país.

Por ello, el objetivo general de esta investigación fue evaluar el efecto del resveratrol en el porcentaje y calidad de embriones in vitro generados por separación de blastómeras en ganado bovino.

\section{MATERIAL Y MÉTODOS}

Localización del estudio y materiales utilizados. El estudio se realizó en el Laboratorio de biotecnología animal, reproducción y mejoramiento genético del Instituto de Investigación en ganadería y biotecnología, Universidad Nacional Toribio Rodríguez de Mendoza, región Amazonas, Perú.

Colecta de ovarios y aspiración de los ovocitos. Se colectaron ovarios de vacas cruce con Brown Swiss, con un rango de edades de 1 a 4 años, fisiológicamente sanas. Los ovarios fueron recolectados en vacas de la cuidad de Chachapoyas con ayuda de tijeras y posteriormente se transportaron al laboratorio en un recipiente isotérmico conteniendo cloruro de sodio al $0.9 \%$ (wt/vol) con $0,025 \mathrm{mg} / \mathrm{ml}$ de estreptomicina, temperado a $37^{\circ} \mathrm{C}$. Se aspiraron los folículos de tamaño medio (2 a $6 \mathrm{~mm}$ ) usando una jeringa de $10 \mathrm{ml}$ y una aguja de $18 \mathrm{G}$ con medio de manipulación HEPES suplementado con $50 \mathrm{mg} / \mathrm{ml}$ de gentamicina y $10 \%$ (vol/vol) de suero fetal bovino (SFB).

Maduración in vitro de los ovocitos. Fueron seleccionados los ovocitos con citoplasma homogéneo y varias capas de células de cúmulos compactos ${ }^{11,17}$. La maduración in vitro fue realizada en 24 horas, en una atmósfera humidificada con $5 \% \mathrm{CO}$ a $38,5^{\circ} \mathrm{C}$, en placas de 4 celdas conteniendo medio de maduración TCM199 suplementadas con $0,25 \mathrm{mg} / \mathrm{ml}$ de piruvato de sodio, $50 \mathrm{ug} / \mathrm{ml}$ de gentamicina, $0,01 \mathrm{UI} / \mathrm{ml}$ de hormona folículo estimulante (FSH), 0,01 UI/ml de hormona luteinizante (LH), $0,1 \mathrm{mg} / \mathrm{ml}$ de glutamina, $10 \mathrm{ng} / \mathrm{ml}$ de factor de crecimiento epidermal (EGF), $1 \mathrm{ug} / \mathrm{ml}$ de 17 B-estradiol y $10 \%$ SFB.

Fertilización in vitro de los ovocitos. Para la fertilización se utilizó semen nacional congelado de la raza Brangus. Espermatozoides mótiles fueron lavados, seleccionados y capacitados por el método de Percoll ${ }^{14}$ y adicionados al medio de fecundación TALP-FIV ${ }^{20}$; suplementado con $0,25 \mathrm{mg} / \mathrm{ml}$ de piruvato de sodio, 50 ug de gentamicina, $0,03 \mathrm{mg} / \mathrm{ml}$ de heparina y $3 \mathrm{mg} / \mathrm{ml}$ de suero de albumina bovina factor cinco (BSAV). Los ovocitos madurados y los espermatozoides capacitados se incubaron por 18 horas en una atmósfera humidificada a $38,5^{\circ} \mathrm{C}$ con $5 \% \mathrm{CO}_{2}$.

Cultivo in vitro de los cigotos. Ellos se cultivaron en grupos de 25 en placas de cuatro pocillos durante tres días a $38,5^{\circ} \mathrm{C}$, con mezcla de gases, utilizando el medio SOF base ${ }^{20}$; suplementado con $0,044 \mathrm{~g} / \mathrm{l}$ de piruvato de sodio, $0,039 \mathrm{~g} / 1 \mathrm{de}$ L-glutamina, $3,0 \mathrm{mg} / \mathrm{ml}$ 
Tabla 1. Clivaje y producción de embriones.

\begin{tabular}{|c|c|c|c|c|c|}
\hline \multirow[b]{2}{*}{ grupo } & \multirow{2}{*}{$\begin{array}{c}\mathrm{N}^{\circ} \mathrm{de} \\
\text { ovocitos }\end{array}$} & \multicolumn{4}{|c|}{ embriones en el día 3} \\
\hline & & $\begin{array}{c}\mathrm{N}^{\circ} \text { emb.clivados } \\
\pm \text { E.E.M }\end{array}$ & $\begin{array}{l}\% \text { embr. } \\
\text { clivados }\end{array}$ & $\begin{array}{c}\mathrm{N}^{\circ} \text { de emb. } 8-10 \text { blast. } \\
\pm \text { E.E.M }\end{array}$ & $\begin{array}{l}\% \text { emb. } \\
8-10 \text { blast. }\end{array}$ \\
\hline $2 \mu \mathrm{M}$ & 300 & $149 \pm 1,1^{\mathrm{a}}$ & 50 & $67 \pm 0,4^{b}$ & 22 \\
\hline $0,5 \mu \mathrm{M}$ & 300 & $156 \pm 0,7^{\mathrm{a}}$ & 52 & $77 \pm 0,4^{\mathrm{a}}$ & 26 \\
\hline control & 300 & $155 \pm 0,9^{\mathrm{a}}$ & 52 & $66 \pm 0,5^{b}$ & 22 \\
\hline
\end{tabular}

${ }_{\mathrm{a}, \mathrm{b}}$ superindices diferentes dentro de las columnas indican diferencia estadística $(\mathrm{p}<0,05), \pm$ error estándar de la media.

de suero de albumina bovina (BSA-FAF), $1 \mathrm{X}$ de aminoácidos esenciales, $1 \mathrm{X}$ de amino ácidos no esenciales, $10 \mathrm{mg} / \mathrm{ml}$ de EGF, $0,1 \mathrm{mg} / \mathrm{ml}$ de ácido cítrico, $0,5 \mathrm{mg} /$ $\mathrm{ml}$ de myo-inositol, $50 \mu \mathrm{g} / \mathrm{ml}$ de gentamicina, $2 \%$ de SFB y dos concentraciones de resveratrol de $2 \mu \mathrm{M}$ y $0,5 \mu \mathrm{M}$.

Separación de blastómeras y cultivo en WOW. Los embriones de tres días de cultivo con ocho a diez blastómeras fueron despojados de su zona pelúcida con $0,2 \%$ de pronasa en Hepes-buffered SOF para ser cultivados en WOW (pocillos hechos manualmente con un punzón) a razón de cuatro blastómeras por pocillo, con el medio de cultivo SOF mencionado anteriormente y suplementado con concentraciones de $2 \mu \mathrm{M}$ y $0,5 \mu \mathrm{M}$ de resveratrol, posteriormente se colocaron en incubadora de $\mathrm{CO}_{2}$ durante 6 días.

Tinción de yoduro de propidio (PI) (células muertas), flurescein diacetate (FDA) (células vivas) y Hoechst (células totales). Pasados los seis días de cultivo los embriones fueron colocados en medio de tinción compuesto por phosphate buffered saline-alcohol polivinílico suplementado con $1,0 \mathrm{mg} / \mathrm{ml}$ de PI, 1,0 $\mathrm{mg} / \mathrm{ml}$ de FDA y $1,0 \mathrm{mg} / \mathrm{ml}$ de Hoechst para luego ser llevados a incubación por 10 minutos y posteriormente ser examinados con ayuda de un microscopio invertido con fluorescencia (Oly mpus, Japón).

Análisis estadístico. Los datos de clivaje, desarrolo embrionario, producción de embriones, cantidad de células totales y células vivas obtenidos en las 4 repeticiones por tratamiento $(2 \mu \mathrm{M}, 0,5 \mu \mathrm{M})$ y grupo control (sin aplicación de resveratrol) se analizaron mediante el análisis de varianza (ANOVA) en un diseño completamente al azar (DCA) usando el software estadístico Statistix $16.0^{18}$.

\section{RESULTADOS}

La suplementación con resveratrol al día 3 de cultivo no alteró la tasa de clivaje (50, 52 y $52 \%$ ); sin embargo la suplementación de resveratrol con $0.5 \mu \mathrm{M}$ fue significativamente superior $(p<0,05)$ en $4 \%$ respecto a los otros grupos en número de embriones de 8 a 10 blastómeros (Tabla 1 y Figura 1).

El número y porcentaje de blastocistos al sexto día de cultivo post separación de blastómeras no presentó diferencia al nivel de $\mathbf{p}<0,05$ (Tabla 2, Figura 5), sin embargo se notó una superioridad numérica al agregar $0,5 \mu \mathrm{M}$ respecto a los otros tratamientos.

La concentración de $0,5 \mu \mathrm{M}$ de resveratrol en el cultivo post-separación de blastómeras superó $(p<0,05)$
Tabla 2. Blastocistos producidos post separación de blastómeros a los seis días de cultivo según la concentración de resveratrol y grupo control.

\begin{tabular}{cccc}
\hline grupo & $\begin{array}{c}\mathrm{N}^{\circ} \text { de embr. } \\
\text { cultivados en } \\
\text { WOW (4 blast.) }\end{array}$ & $\begin{array}{c}\mathrm{N}^{\circ} \text { blast. post } \\
\text { separación de blastó- } \\
\text { meros ( } \pm \text { E.E.M) }\end{array}$ & $\begin{array}{c}\text { \% blast. post } \\
\text { separación de } \\
\text { blastómeros }\end{array}$ \\
\hline $2 \mu \mathrm{M}$ & 86 & $37 \pm 0,3$ & 43 \\
$0,5 \mu \mathrm{M}$ & 98 & $45 \pm 0,2$ & 46 \\
control & 88 & $36 \pm 0,5$ & 41 \\
\hline
\end{tabular}

$1 \pm$ error estándar de la muestra.

Tabla 3. Células totales y células vivas en blastocistos obtenidos post separación de blastómeras a 6 días de cultivo con dos concentraciones de resveratrol y un grupo control.

\begin{tabular}{cccc}
\hline \multicolumn{4}{c}{ embriones $6^{\circ}$ día post-separación de blastómeros } \\
\hline Grupo & $\begin{array}{c}\mathrm{N}^{\circ} \\
\text { embriones }\end{array}$ & $\begin{array}{c}\mathrm{N}^{\circ} \text { células totales } \\
( \pm \text { E.E.M })\end{array}$ & $\begin{array}{c}\mathrm{N}^{\circ} \text { células vivas } \\
( \pm \text { E.E.M) }\end{array}$ \\
\hline $2 \mu \mathrm{M}$ & 37 & $87 \pm 0.6^{\mathrm{b}}$ & $84 \pm 0.2^{\mathrm{b}}$ \\
$0,5 \mu \mathrm{M}$ & 45 & $96 \pm 1.0^{\mathrm{a}}$ & $93 \pm 0.3^{\mathrm{a}}$ \\
control & 36 & $86 \pm 0.8^{\mathrm{b}}$ & $83 \pm 0.2^{\mathrm{b}}$ \\
\hline
\end{tabular}

${ }^{a, b}$ Superíndices diferentes dentro de las columnas indican diferencia estadística $(\mathrm{p}<0,05), \pm$ error estándar de la media.

en 9 y 8 células totales con respecto a $2 \mu \mathrm{M}$ y el grupo control. Asímismo presentó superioridad en número de células vivas la suplementación con $0,5 \mu \mathrm{M}$ de resveratrol respecto al $2 \mu \mathrm{M}$ y al control, como se muestra en la Tabla 3.

\section{DISCUSIÓN}

Según los investigadores ${ }^{19}$, el uso de resveratrol en la fecundación ayuda a contrarrestar la poliespermia dando por consiguiente mejores resultados en clivaje y producción de embriones en bovinos. En la presente investigación se agregaron las dosis de resveratrol posteriormente a las 18 horas de fecundación, donde éste ya no tuvo contacto con los espermatozoides, sino directamente con los cigotos ya fecundados, por lo cual en los resultados no hubo diferencias en clivaje por tratamientos y grupo control.

Otros investigadores reportaron que la adicion de resveratrol en los medios de cultivo para la producción de embriones in vitro tiene un efecto positivo en su calidad ya que disminuye los procesos de apoptosis ${ }^{15}$

Ello fue corroborado por otros investigadores ${ }^{21}$, los cuales determinaron que la suplementación con altas o bajas concentraciones de resveratrol no influyen en 


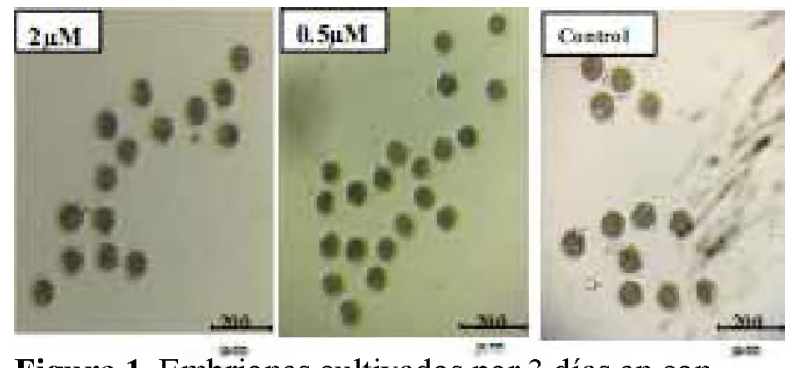

Figura 1. Embriones cultivados por 3 días en concentraciones de $2 \mu \mathrm{M}, 0.5 \mu \mathrm{M}$ de resveratrol y grupo control presentando ocho a diez blastómeros.

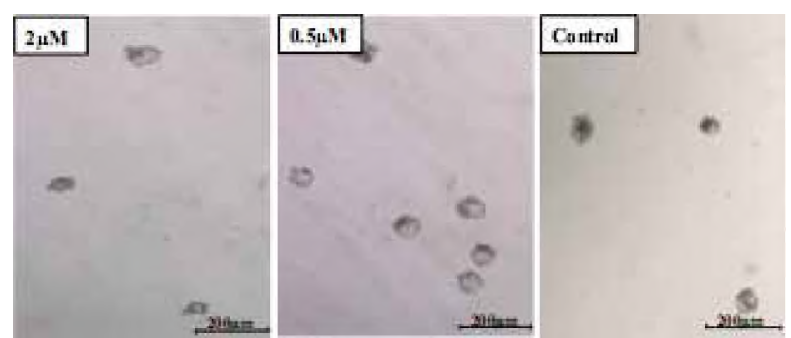

Figura 2. Blastocistos producidos post separación de blastómeras a los seis días de cultivo.

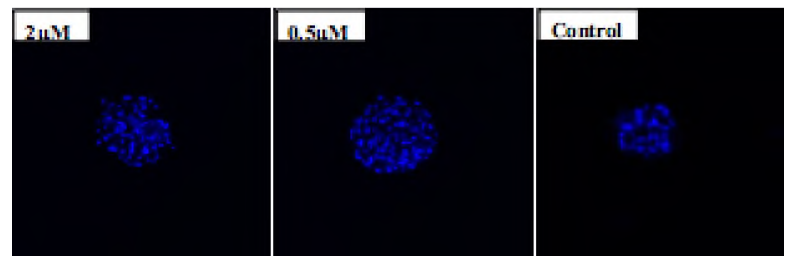

Figura 3. Determinación de células totales con tinción Hoechst en blastocistos.

las tasas de producción in vitro de blastocistos bovinos; sin embargo respaldan que las bajas concentraciones de su suplementación en los medios de cultivo mejoran la calidad de los embriones bovinos.

Estos resultados concuerdan con los obtenidos en la presente investigación, donde no se observaron diferencias significativas $(p<0,5)$ en la tasa de producción de blastocistos con el uso de resveratrol, lo cual podría también haber estado influenciado por la manipulación en la separación de blastómeros aumentando el estrés oxidativo que resulta en altos niveles tóxicos de ROS, perjudicando su desarrollo embrionario 1,8

Por su parte, los resultados en calidad embrionaria fueron similares respecto al promedio del número de células totales $(96,0)$ y el promedio de células vivas por embrión, lo cual indica que la adición de resveratrol en el medio de cultivo a una concentración de $0,5 \mu \mathrm{M}$ tiene efecto positivo en la calidad de los embriones producidos por separación de blastómeras.

La mejoría en la calidad embrionaria respecto al número de células totales es corroborada por varios investigadores ${ }^{10,16}$, quienes realizaron estudios con resveratrol en la producción de embriones in vitro en cerdos y bovinos, teniendo mejores resultados con la concentración de $0,5 \mu \mathrm{M}$, concordando con estos re- sultados, que usando la misma cantidad de resvertarol presentó mejor calidad (Tabla 3, Figura 3).

Otros ${ }^{4}$ reportaron mejores resultados en el proceso de vitrificación de ovocitos porcinos con una concentración de $2 \mu \mathrm{M}$ por lo cual se tomó en consideración esta concentración por ser también la separación de blastómeras un proceso que provoca estrés fuera del desarrollo normal de un embrión. Sin embargo esta concentración de resveratrol no tuvo efecto positivo sobre el porcentaje y la calidad de blastocistos (Tabla 2, Tabla 3).

En conclusión, surge que la suplementación con resveratrol al medio SOF no aumenta el porcentaje de blastocistos pero sí mejora su calidad al usar una concentración de $0,5 \mu \mathrm{M}$.

Agradecimientos: al Instituto de Investigación en Ganaderia y Biotecnología de la UNTRM-A por el apoyo en el financiamiento para el desarrollo de la investigación

\section{REFERENCIAS}

1. Galeati G, Spinaci M. 2015. Resveratrol from red grapes: an useful agent for oocyte maturation and subsequent embryonic development. Austin Journ Fertil 2: 1-3.

2. Gaviria $\mathbf{S}$ et al. 2018. Resveratrol supplementation promotes recovery of lower oxidative metabolism after vitrification and warming of in vitro produced bovine embryos. Reprod Fertil \& Develop 31: 521-528.

3. Gambini J et al. 2013. Resveratrol: distribución, propiedades y perspectivas. Rev Españ Geriat \& Gerontol 48: 79-88.

4. Giaretta E, Spinaci M, Bucci D, Tamanini C, Galeati G. 2013. Effects of resveratrol on vitrified porcine oocytes. Oxid. Med. Cell. Longev. ID 920257. DOI: $10.1155 / 2013 / 920257$.

5. Huang L, Shiao N, Hsuuw Y, Chan W. 2007. Protective effects of resveratrol on ethanol-induced apoptosis in embryonic stem cells and disruption of embryonic development in mouse blastocysts. Toxicology 242: 109-122.

6. Jhonson W, Loskutoff N, Plante Y, Betteridge K. 1995. Production of four identical calves by the separation of blastomeres from an in vitro derived four cell embryo. Vet Record 137: 15-16.

7. Johnson M, Nasr E.M. 1994. Radical solutions and cultural problems: could free oxygen radicals be responsible for the impaired development of preimplantation mammalian embryos in vitro. BioEssays 16: 31-38.

8. Kitagawa Y, Suzuki K, Yoneda A, Watanabe T. 2004. Effects of oxygen concentration and antioxidants on the in vitro development a lability, production of reactive oxygen species (ROS), and DNA fragmentation in porcine embryos. Theriogenology 62: 1186-1197.

9. Kwak S, Cheong S, Jeon Y, Lee E, Choi K. 2012. The effects of resveratrol on porcine oocyte in vitro matu ration and subsequent embryonic development after parthenogenetic activation and in vitro fertilization. Theriogenology 78: 86-101. 
10. Lee K, Wang C, Chaille JM, Machaty Z. 2010. Effect of resveratrol on the development of porcine embryos produced in vitro. J Reprod Dev 56: 330-335.

11. Liebfried L, First, N. 1979. Characterization of bovine folicular oocytes and their ability to mature in vitro. $J$ Anim Sci 48: 76-86.

12. Liu Y et al. 2013. Resveratrol protects mouse oocytes from methyl glyoxal induced oxidative damage. PLoS One 8-10.

13. Nasresfahani M, Aitken J, Johnson M. 1990. Hydrogen peroxide levels in mouse oocy tes and early cleavage stage embryos developed in vitro or in vivo. Development 109 : 501-507.

14. Parrish J, Krogenaes A, Susko PJ. 1995. Effect of bovine sperm separation by swim up orpercoll on success of in vitro fertilization and embryo development. Theriogenology 44: 859-870.

15. Pirola L, Fröjdö S. 2008. Resveratrol: one molecule, many targets. IUBMB Life, 60: 323-332.
16. Salzano A et al. 2014. Effect of resveratrol supplementation during culture on the quality and cryotolerance of bovine in vitro produced embryos. Anim Reprod Science 151: $3-4$.

17. Sato E, Matsuo M, Miyamoto H. 1990. Meiotic maturation of bovine oocytes in vitro: Improvement of meiotic competence by dibutyryl cyclic adenosine 3'5'monophosphate. J Anim Sci 68: 1182-1187.

18. SPSS Inc. 2007. SPSS for Windows, version 16.0. SPSS Inc., Chicago.

19. Takeo $\mathrm{S}$ et al. 2014. Resveratrol improves the mitocondrial function and fertilization outcome of bovine oocytes. Journal Reprod \& Develop 60: 92-99.

20. Vajta $\mathbf{G}$ et al. 2000. New method for culture of zona-included or zona free embryos: the well-of-the well (WOW) system. Mol Reprod Dev 55: 256-264.

21. Zullo G. 2015. Natu ral antioxidants during in vitro culture improve embryo quality in cattle. Repositorio.untrm.edu. pe $>$ bitstream $>$ handle $>$ UNTRM. Tesis Doctoral, p.1-162.

\section{Revista Veterinaria obtuvo el máximo nivel de categorización del CAICYT-CONICET}

Tras el pertinente proceso de evaluación según criterios de calidad editorial, en setiembre de 2005 CAICYT-CONICET ha clasificado a nuestra publicación con Categoría 1 (nivel superior de excelencia), con lo cual pasa a integrar el Catálogo Latindex (folio 14022). La Dirección de Revista veterinaria agradece a quienes colaboraron para obtener tan importante distinción.

Ver: http://www.latindex.unam.mx/busquedas/catalogotitulo.html 